\title{
TRANSMISSION ELECTRON MICROSCOPY OF PLUTONIUM
}

R. Busch

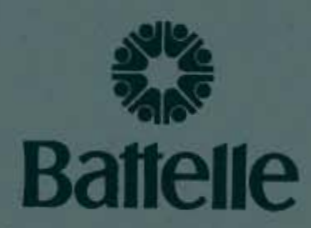

Pacific Northwest Laboratories

Richland, Washington 99352

\section{AUGUST 1974}

Prepared for the U.S. Atomic Energy

Commission under Contract AT(45-1):1830 


\title{
NOTICE
}

The report was prepared as an account of work sponsored by the United States Government. Neither the United States nor the United States Atomic Energy Commission, nor any of their employees, nor any of their contractors, subcontractors, or their employees, makes any warranty, express or implied, or assumes any legal liability or responsibility for the accuracy, completeness or usefulness of any information. apparatus, product or process disclosed, or represents that its use would not infringe privately owned rights.

\author{
PACIFIC NORTHWEST LABORATORY \\ operated by \\ BATTELLE \\ for the \\ U.S. ATOMIC ENERGY COMMISSION \\ Under Contract AT(45-1)-1830
}

\author{
Printed in the United States of America \\ Available from \\ National Technical Information Service \\ U.S. Depariment of Commerce \\ 5285 Port Royal Road \\ Springfield, Virginia 22151 \\ Price: Printed Copy \$4.00; Microfiche \$1.45
}


BNWL-1863

UC-2, General, Miscellaneous, and Progress Reports

\section{TRANSMISSION ELECTRON MICROSCOPY OF PLUTONIUM}

by

R. Busch

August 1974

BATTELLE

PACIFIC NORTHWEST LABORATORIES

RICHLAND, WASHINGTON 99352 


\section{IABLE OF CONTENTS}

INTRODUCTION •

EXPERIMENTAL PROCEDURES . . . . . . . . . . . . . . 2

Specimen Preparation . . . . . . . . . . . . . . 2

Electron Diffraction . . . . . . . . . . . 6

Electron Beam Intensity . . . . . . . . . . . . . 8

RESULTS AND DISCUSSION . . . . . . . . . . . . 10

General . . . . . . . . . . . . . 10

Unalloyed Plutonium . . . . . . . . . . . . . . 10

Plutonium-1 Wt\% Gallium Alloy . . . . . . . . . . . 11

Plutonium-5 Wt\% Tantalum Alloy . . . . . . . . . . . 15

Plutonium-1 Wt\% Zirconium Alloy . . . . . . . . . . 17

Comparison with Bulk Sputter Deposited Material Behavior . . 17

Ion Thinning . . . . . . . . . . . . . . . . . 20

SUMMARY AND CONCLUSIONS . . . . . . . . . . . . . . . . 21

REFERENCES . . . . . . . . . . . . . . . . . . . 24 


\section{TRANSMISSION ELECTRON MICROSCOPY OF PLUTONIUM}

\section{INTRODUCTION}

Although transmission electron microscopy (TEM) has produced a wealth of otherwise unobtainable information on materials since its first reported application almost twenty years ago, there has been little published on attempts to apply this technique to plutonium. Brewer ${ }^{(1)}$ reported preliminary results on plutonium 1 wt\% gallium thinned by electropolishing; however, Douglass ${ }^{(2)}$ suggested that these experiments actually involved the oxide rather than the metal.

The motivation for applying TEM to plutonium and its alloys arises from the resolution of the instrument, which is between two and three orders of magnitude greater than optical microscopes, and the ability to obtain structural information from the "bulk" of a sample rather than only the surface. The significance of these factors is best appreciated by considering the advance in understanding made in other materials by the application of TEM. ${ }^{(3)}$ The motivation is particularly strong in the case of sputter deposited plutonium and its alloys, where very fine-grained structures may be produced $(4)$ and where the actual distribution of alloying elements can profoundly affect the macroscopic properties, such as allotropic behavior, of the material. (5)

The difficulties anticipated in TEM of plutonium arise from its high density and reactivity, and its low thermal conductivity. The high density (15.7 to $19.7 \mathrm{~g} \mathrm{~cm}^{-3}$ for the different allotropes) implies that the maximum thickness which is transparent to electrons will be much smaller than 
for other materials which have been successfully examined. The maximum thickness was estimated to be about $20 \mathrm{~nm}$ for the $100 \mathrm{kV}$ instrument available. The difficulty of the thinning process was expected to increase as the required thickness decreased. Secondly, the reactivity of plutonium with oxygen and/or water vapor is such that even at room temperature a substantial fraction of the $20 \mathrm{~nm}$ thick sample would be converted to oxide during the transfer from the thinning apparatus to the microscope. The process would also continue while the sample was in the microscope, since the vacuum in commercially available instruments is on the order of $10^{-5}$ torr or worse. Finally, the low thermal conductivity implied that the sample temperature would rise during observation due to the energy input from the electron beam. This temperature rise would increase the oxidation rate, and might induce a phase transformation.

Several means of overcoming these difficulties were considered, as detailed below. A limited degree of success was obtained, and observations of several plutonium alloys were made.

\section{EXPERIMENTAL PROCEDURES}

\section{Specimen Preparation}

Two studies were carried out with emphasis on separate problems expected in TEM of plutonium. The first study concentrated on means of protecting a thin foil of plutonium during transfer to the microscope and observation. The thin foils were prepared by sputter deposition at deposition rates and times calculated to produce $20 \mathrm{~nm}$ thickness. Protection was supplied by thin layers of light metals on either side of 
the plutonium foil. The second study concentrated on thinning procedures that would be compatible with the above protection.

A11 depositions were performed in an all metal, bakeable sputtering system set up as shown in Fig. 1. The shutter and light metal target were rotatable. The substrate temperature was controlled by either water or nitrogen gas coolant, and measured with a thermocouple in contact with the rear surface.

A typical experiment began with evacuation to $\sim 10^{-8}$ torr and backfilling to 3-5 millitorr with research grade krypton gas. The copper substrate, which had been coated with a parting layer, was protected by the shutter while a plasma was ignited and the light metal target was cleaned by ion etching. Once the desired operating conditions had been achieved, the shutter was pivoted into the open position for a predetermined period, to produce a nominal $10 \mathrm{~nm}$ thick deposit. Deposition was terminated with the shutter. The light metal target was then swung off axis and the plutonium target was ion etched. The shutter was operated to produce a $20 \mathrm{~nm}$ thick plutonium deposit. Finally, the light metal target operation was repeated to provide a second protective layer. The resulting deposit is illustrated schematically in Fig. 2. The protected plutonium sample was removed from the substrate by dissolution of the parting layer in acetone and was examined in a JEM $7 \mathrm{~A}$ electron microscope at $100 \mathrm{kV}$.

A variety of parting layers were tested, including colloidal graphite, cellulose acetate and other polymeric materials, and common salt. Cellulose 


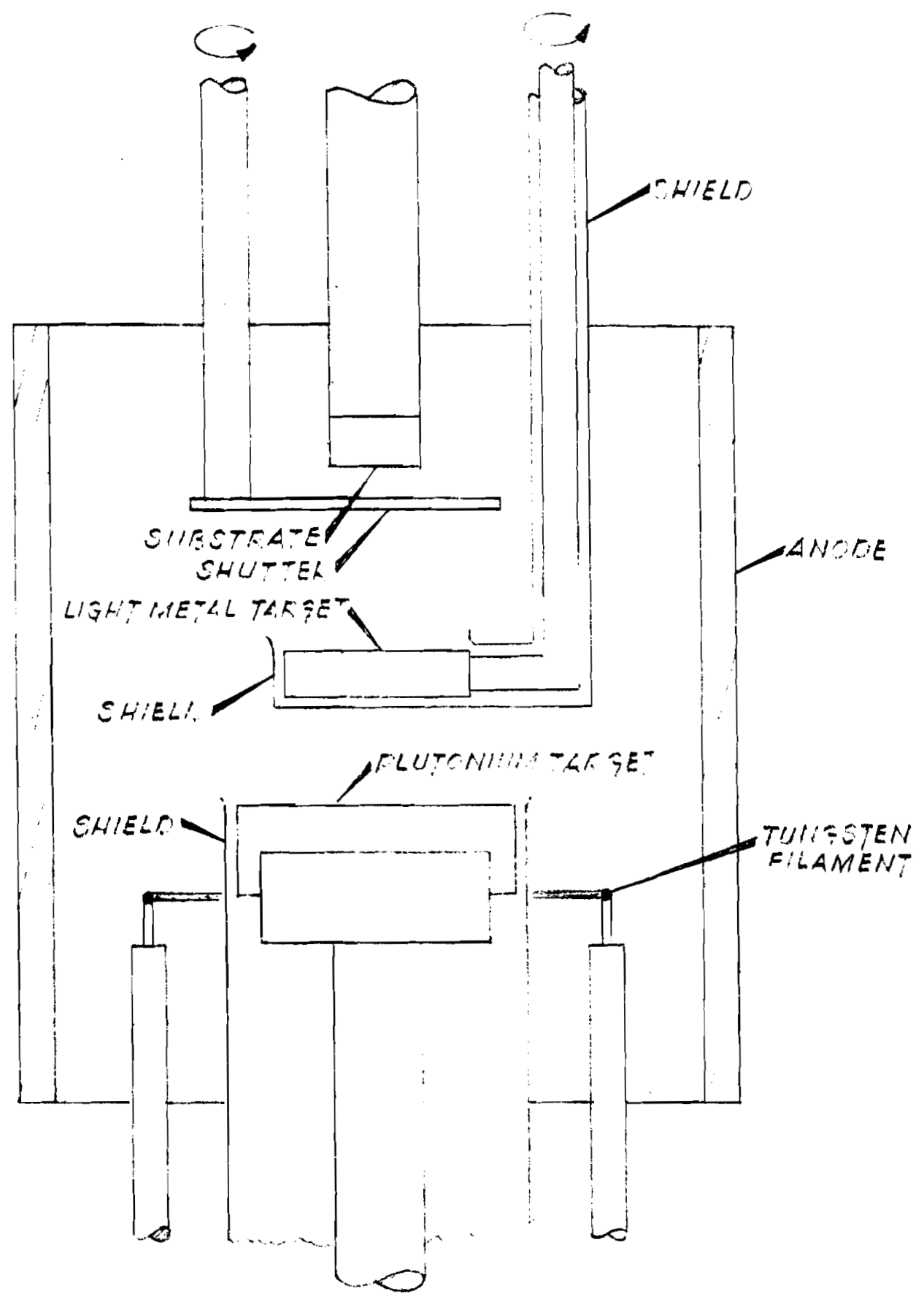

Figure 1

Schematic representation of sputtering apparatus used for deposition of plutonium specimens for TEM. 


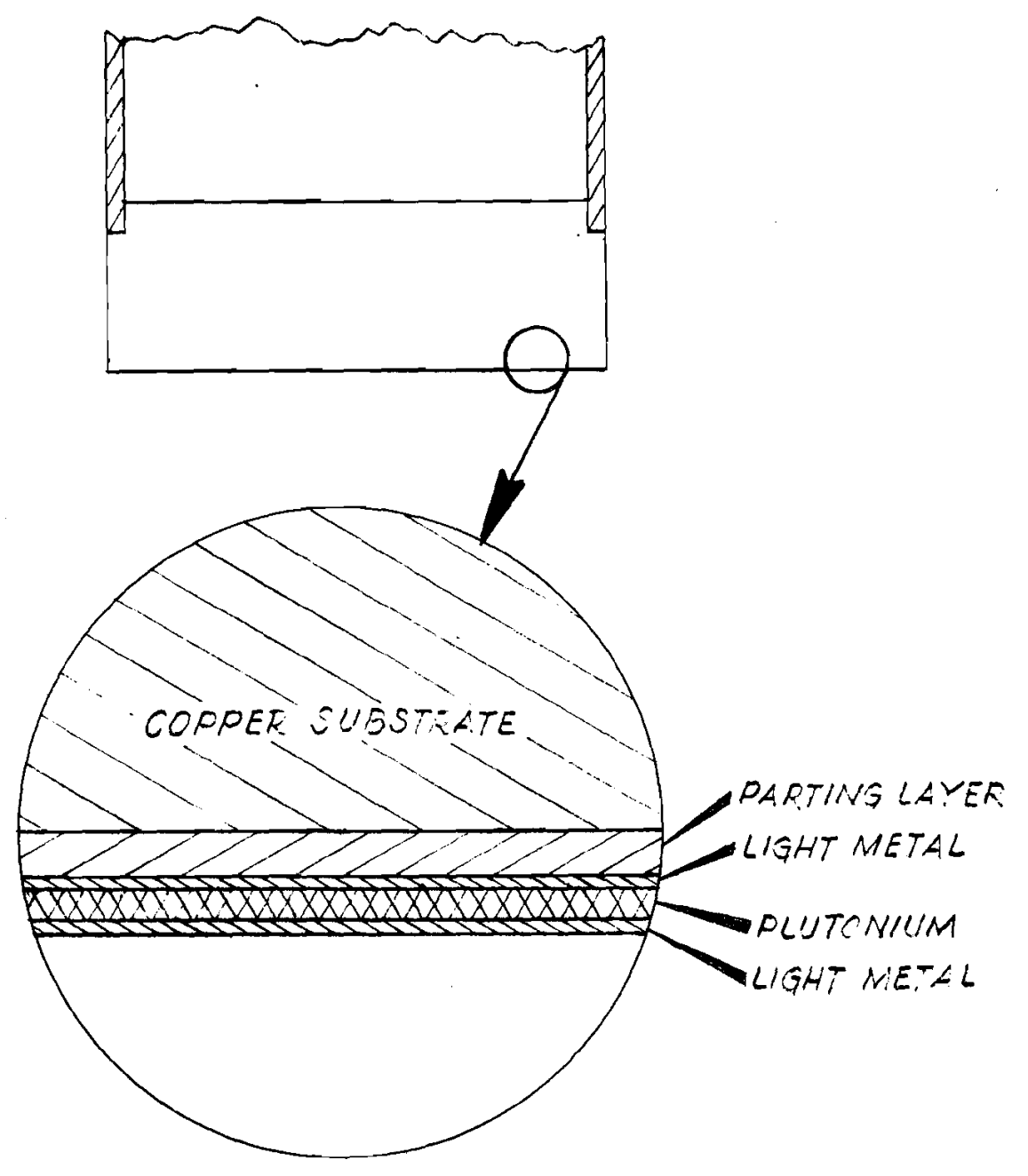

Figure 2

Schematic representation of plutonium TEM specimen, deposited with its protective light metal layers and a parting layer on a copper substrate. 
acetate was the only material which performed satisfactorily. It was applied with an eyedropper from a solution of the material in acetone.

Beryllium, magnesium and aluminum were the light metal candidates in order of preference from an electron transmission standpoint. Beryllium was favored because of its low solubility in plutonium. Aluminum was tried primarily because it was felt that it gave a greater chance of producing a crack-free coating.

In the second study, ion thinning was selected as the process most compatible with the protective layers developed above. A commercial ion gun* was set up in the apparatus illustrated in Fig. 3. The specimen to be thinned consisted of a $3 \mathrm{~mm}$ diameter disc previously dished from both sides by jet thinning. It was mounted in a water-cooled copper block which could be moved longitudinally and rotated. A light metal target was mounted at an angle such that it could serve as a target to coat the thinned specimen when the latter was removed from the ion beam. Rotation of the specimen holder permitted thinning from and coating on both surfaces. This study was performed with various nonradioactive materials. Lack of success however, prevented continuation with plutonium. Electron Diffraction

In the present work, the camera constant of the microscope was determined periodically with an evaporated gold film, and the objective lens current was maintained at the value used for calibration when diffraction patterns were photographed. Under these conditions, accuracy of lattice spacing measurements is expected to be $1-2 \%$ with favorable samples. (6)

*Physical Electronics Industries Model 04-131 


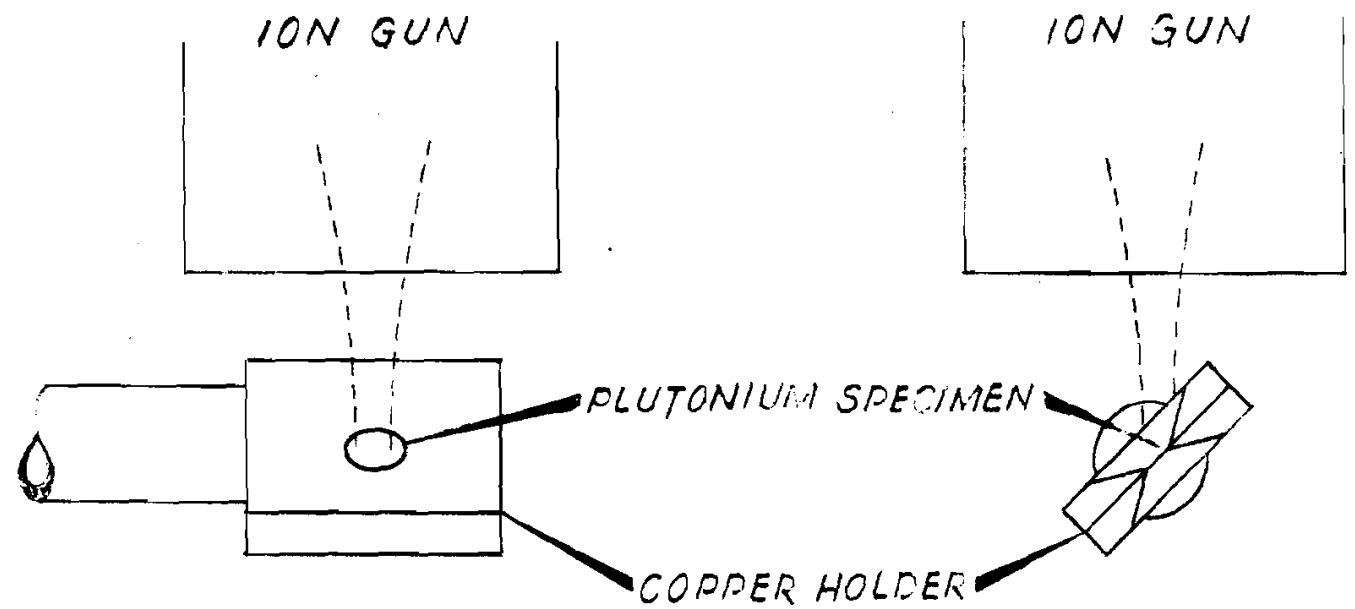

WATER CCOLED SUPDORT

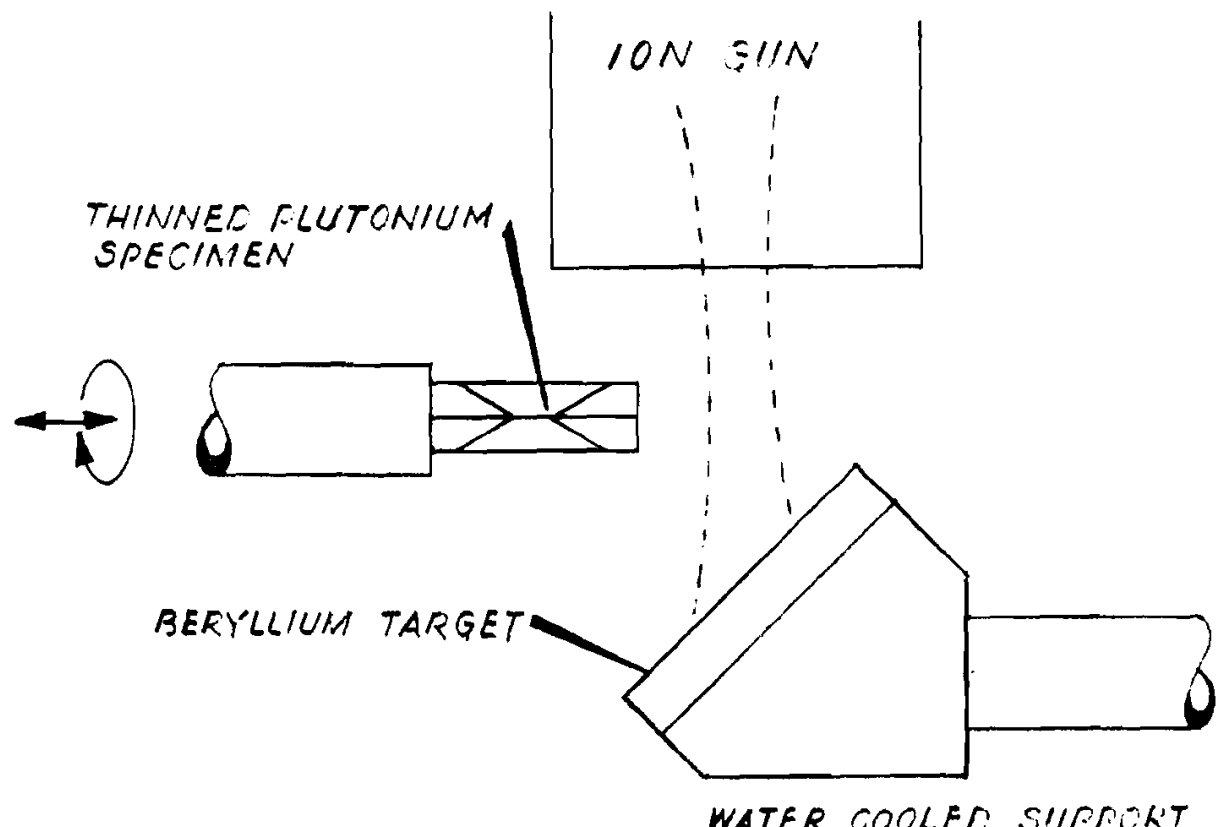

Figure 3

Schematic representation of ion beam apparatus intended for final thinning and protective coating of plutonium TEM specimens. 
"Favorable" implies large enough diffracting domains and low enough strains to avoid broadening of the diffraction rings. These conditions were met only in the final annealed structures; a larger error must be accepted in the broadened ring patterns. In the case of the plutonium phases present or likely to be present in the alloys investigated, with the exceptions of the delta phase and the oxide, the effect of broadening is magnified by the multiplicity of diffraction lines. Phase identification becomes tentative under these circumstances, particularly if the possibility of multiphase deposits is considered.

A modified listing of the accepted interplanar spacings $(7)$ for various phases are shown in Table I. Groups of spacings within $0.02 \AA$ of each other have been combined into one listing using the central line of the group, since the width of the electron diffraction rings precludes resolution of such closely spaced rings. Spacings in different phases within $0.03 \AA$ have been placed on the same line of the table to reflect the expected accuracy between photographs of separate samples at different times. This table will be used as the basis for phase identification in the following sections.

\section{Electron Beam Intensity}

Heating of the plutonium specimen by the electron beam was expected to be a problem because of the low thermal conductivity of the metal. (8) To minimize this problem, observation was begun with the lowest beam current which would provide a satisfactory image, and the condenser lens was underfocused. This condition, referred to hereafter as "low intensity illumination," produced structural changes in most foils. Once the structure stabilized, the beam intensity was increased first by focusing 


\section{TABLE I. Interplanar Spacings of Plutonium}

Phases for Electron Diffraction

\begin{tabular}{|c|c|c|c|c|}
\hline Alpha & Beta & Delta & Zeta & Oxide \\
\hline & & & 3.16 & \\
\hline & 3.05 & & & 3.08 \\
\hline 2.92 & 2.93 & & & \\
\hline \multicolumn{5}{|l|}{2.87} \\
\hline \multirow[t]{2}{*}{2.78} & & & 2.81 & \\
\hline & & & 2.74 & \\
\hline 2.68 & 2.64 & 2.66 & & 2.67 \\
\hline \multirow[t]{3}{*}{2.59} & 2.60 & & 2.56 & \\
\hline & 2.53 & & 2.51 & \\
\hline & 2.48 & 2.46 & & \\
\hline 2.41 & 2.39 & & 2.37 & \\
\hline \multicolumn{5}{|l|}{2.34} \\
\hline \multirow[t]{3}{*}{2.29} & 2.30 & 2.30 & 2.31 & \\
\hline &, 2.26 & & 2.26 & \\
\hline & & & 2.22 & \\
\hline \multirow[t]{2}{*}{2.17} & 2.18 & & 2.17 & \\
\hline & 2.11 & & 2.11 & \\
\hline \multirow[t]{2}{*}{2.03} & 2.04 & & 2.04 & \\
\hline & & & 1.93 & \\
\hline 1.87 & & & & 1.89 \\
\hline 1.82 & 1.82 & & & \\
\hline 1.77 & 1.75 & 1.76 & & \\
\hline 1.71 & & & 1.72 & \\
\hline 1.67 & 1.64 & 1.63 & 1.66 & 1.62 \\
\hline 1.53 & 1.56 & & 1.55 & 1.55 \\
\hline 1.49 & 1.50 & & 1.51 & \\
\hline
\end{tabular}

1.45

1.39

1.33

1.35 
the condenser lens and then by increasing the beam current until normal brightness was obtained. Further structural changes occurred during this process.

\section{RESULTS AND DISCUSSION}

\section{Genera 1}

The deposition of plutonium specimens with protective coatings was successful. The cellulose acetate parting layer, when carefully dissolved, provided flakes of deposit up to 1-2 mm in size, which was more than adequate for TEM. Beryllium protective layers prevented oxidation of the plutonium during transfer from the sputtering system to the microscope and during TEM observation, even at elevated temperatures. One specimen of delta phase plutonium-1 wt\% gallium alloy was kept in an open front hood for a week without oxidation detectable by electron diffraction.

Aluminum layers were similarly protective, but were unsatisfactory in that they dissolved in the plutonium when heated by the TEM observation beam or in the hot stage.

A plutonium specimen prepared without protective layers exhibited a $\mathrm{PuO}_{2}$ diffraction pattern immediately upon beginning observation. This indicates the necessity as well as the effectiveness of the protective layers.

\section{Unalloyed Plutonium}

An unalloyed plutonium deposit was formed at a rate of $0.7 \mathrm{~nm} / \mathrm{sec}$ on a water-cooled substrate. At the start of observation, with low intensity illumination, the deposit was relatively featureless. Some shadowing contours due to the microscopically uneven substrate surface were visible, 
but no grain structure was observed, and the diffraction pattern was poorly defined. Within a few seconds the structure shown in Fig. 4a develcped. The dark specks grew into the featureless matrix, producing the structure in Fig. $4 \mathrm{~b}$ after 30-45 seconds. Additional 1ines appeared in the diffraction pattern, but the inner, intense rings were still poorly resolved. This structure appeared stable under low intensity illumination. Increasing the intensity produced further grain growth and sharpening of the diffraction pattern, Fig. $4 \mathrm{c}$.

The interplanar spacings derived from the diffraction pattern in Figure $4 \mathrm{c}$ are listed in the first column of Table II. The spacings corresponding to the most intense rings are marked with "S". These four spacings bear a relationship appropriate for an fcc structure with a lattice parameter of $5.57 \AA$; however, no known phase of the actual or potential constituents has such a structure and parameter. Two of these spacings, and three of the remaining five, are appropriate to the alpha phase modification. However, many alpha phase spacings, including those expected to be intense, are absent, and four of the spacings observed cannot be accounted for with the alpha phase. Thus no structure assigniiient can be made.

Plutonium-1 Wt\% Gallium Alloy

A plutonium-1 wt\% gallium alloy was formed under deposition conditions similar to those above. The initial structure is shown in Fig. 5a. This structure was sufficiently stable under low intensity illumination to be photographed. The diffraction pattern consisted of poorly resolved rings. Increasing the beam intensity produced the fine grained structure in Fig. $5 b$. The corresponding diffraction pattern contains many additional rings, all of 

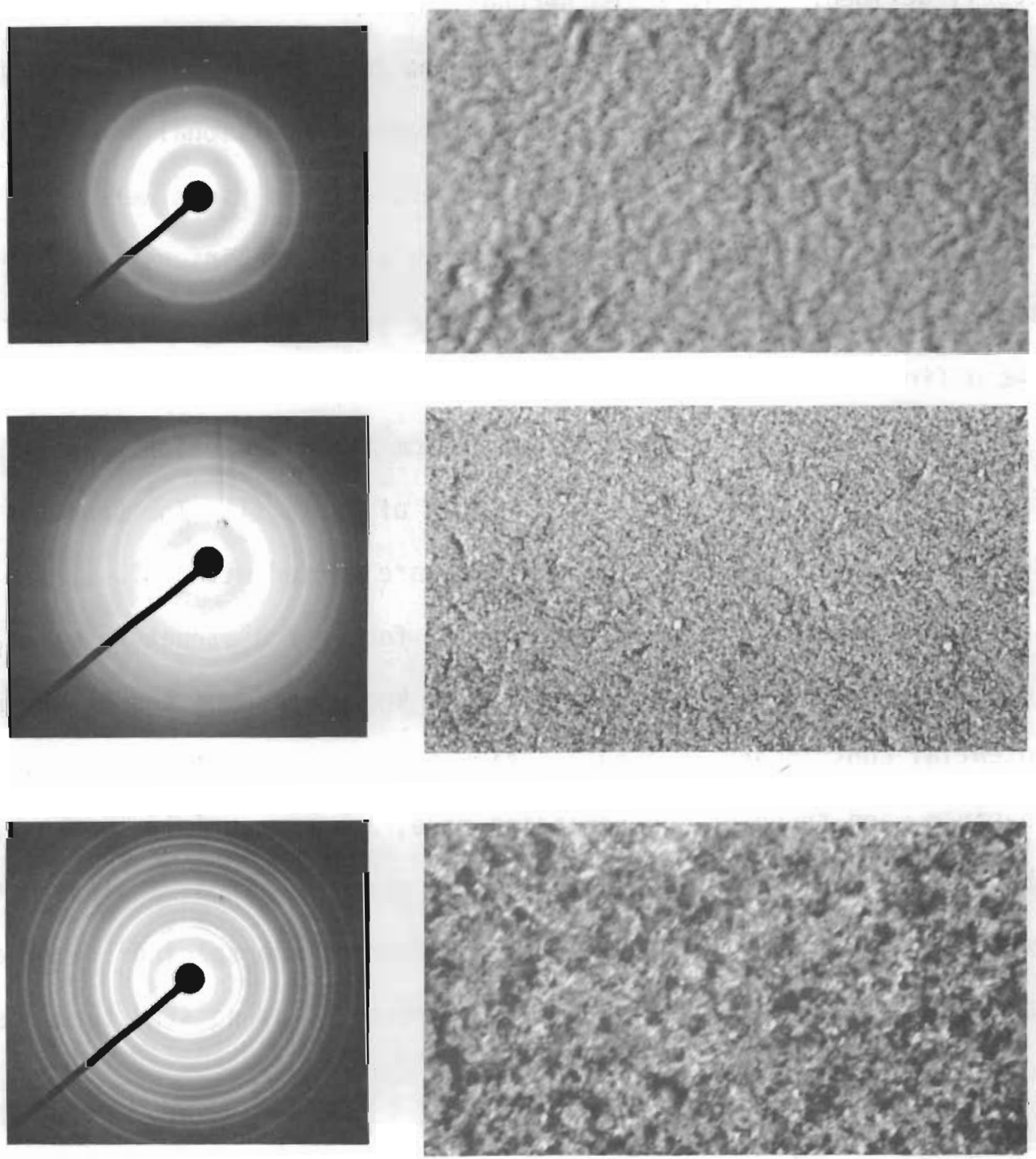

Figure 4

Electron diffraction patterns and photomicrographs of unalloyed plutonium. The degree of annealing by the imaging beam increased from a) to c). 
TABLE II. Interplanar Spacings of Plutonium Specimens after TEM Observation

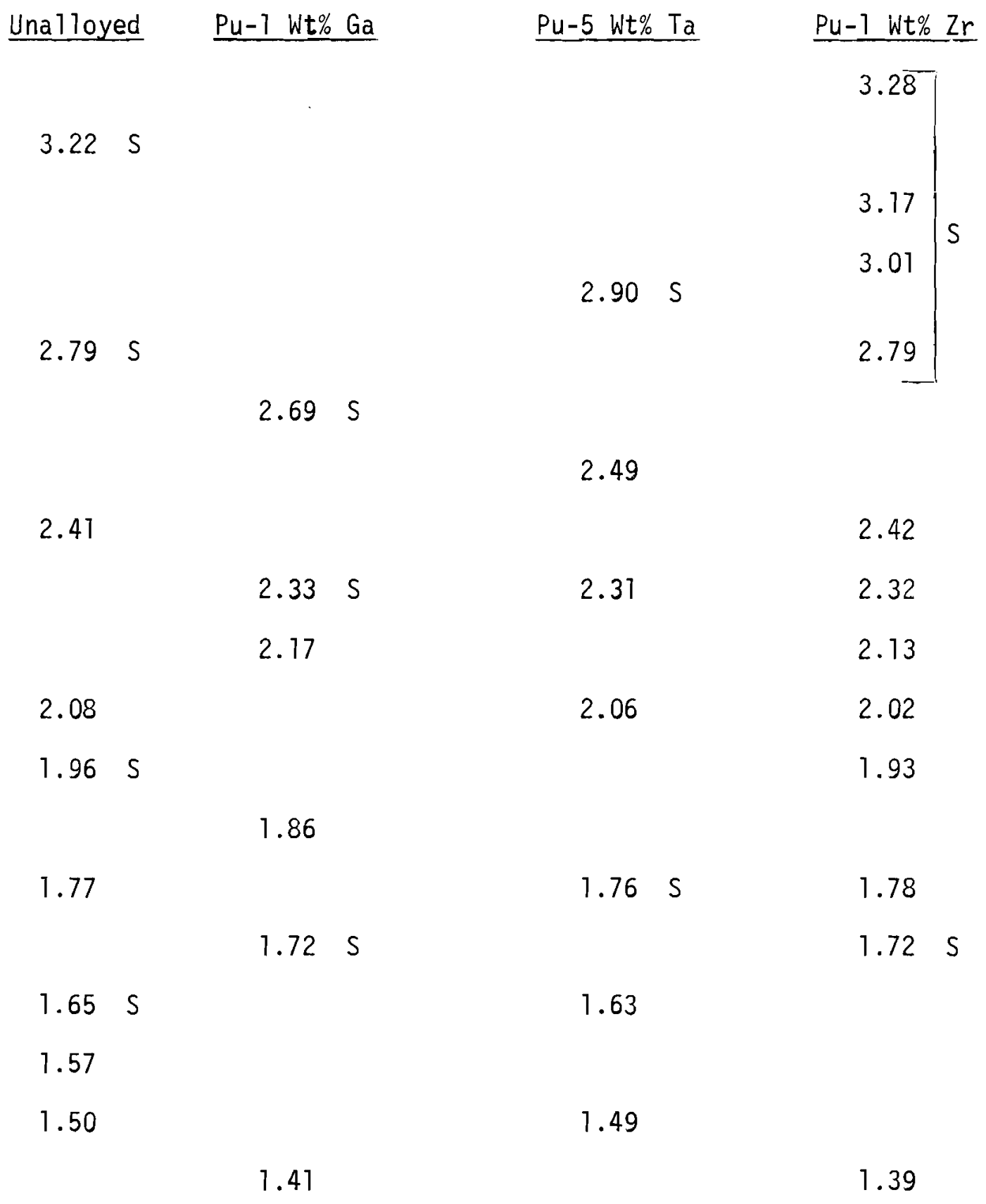



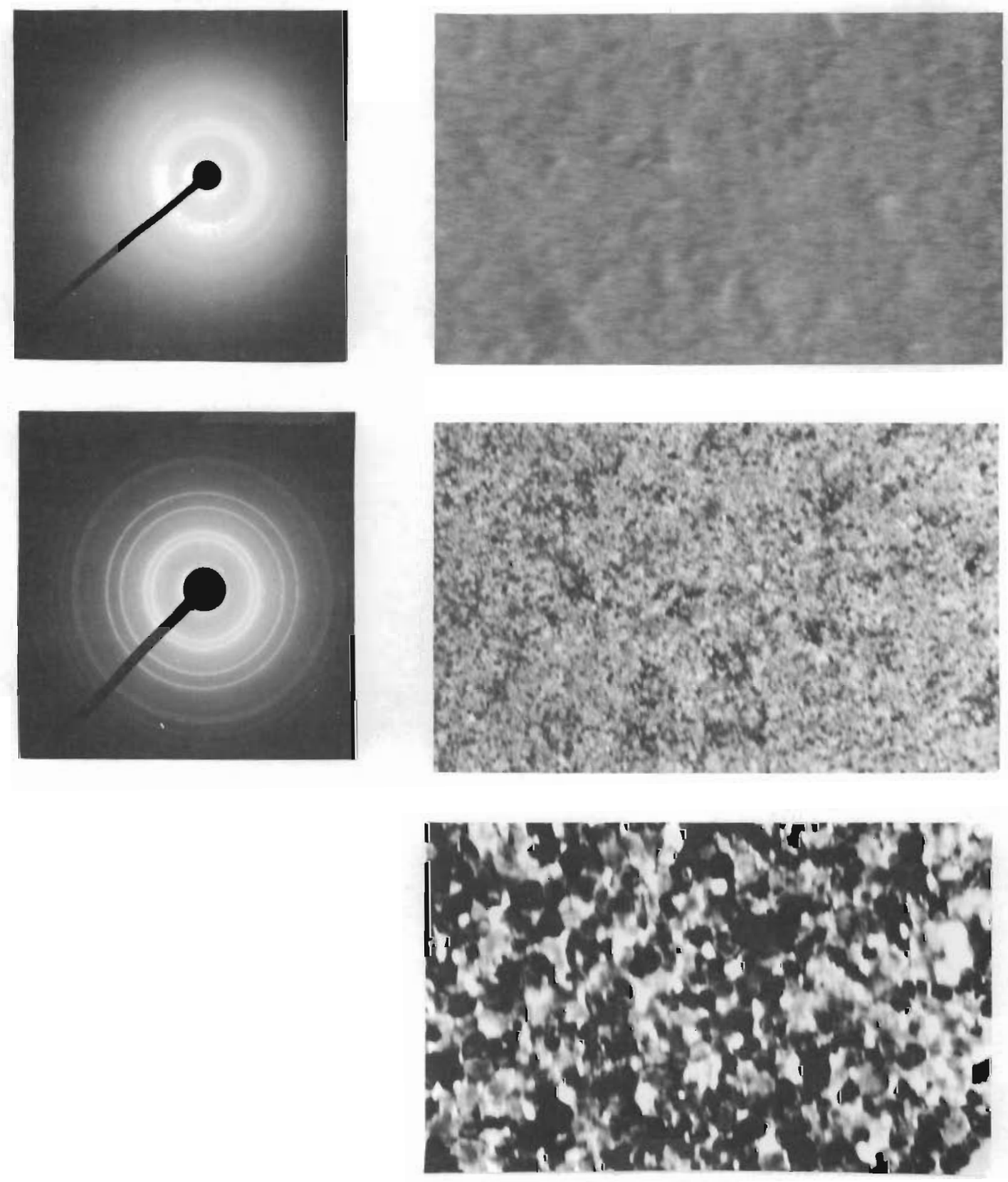

Figure 5

Electron diffraction patterns and photomicrographs of plutonium-1 wt\% gallium alloy. The degree of annealing by the imaging beam increased from a) to c). 
which are well resolved. Further heating of the sample, either by the microscope hot stage furnace or by the use of a very intense electron beam, produced an annealed structure with large $(80 \mathrm{~nm})$ equiaxed grains, Fig. 5c. No further change occurred in the diffraction pattern, and the annealed microstructure was unaffected by further heating/cooling cycles. The interplanar spacings are listed in the second column of Table II. The intense lines fit the fcc delta phase quite well although about $1 \%$ larger than expected, they were within the anticipated measurement error. Two faint 1 ines, 2.17 and $1.86 \AA$, were not accounted for. A1though these spacings were appropriate to the alpha phase, it is unlikeiy that other alpha lines would be either unobserved or masked by the delta lines (see Table I). Therefore it is felt that the presence of alpha as a second phase was not indicated.

\section{Plutonium-5 Wt\% Tantalum Alloy}

A plutonium-tantalum "alloy" was formed from a composite target, under conditions similar to previous depositions. Again the initial structure was featureless. Small grains formed rapidly during observation, Fig. 6a, and developed a relatively sharp diffraction pattern. With continued observation, large irregularly shaped grains formed, Fig. 6b, from the initial set of grains. In many cases, the nucleating grain remained visible. The diffraction pattern at this time was much sharper and contained many additional rings; however, the original rings remained. Finally, with additional heating of the specimen, the structure in Fig. 60 was obtained. At this point the growing grains impinged on each other; no further change was observed. The diffraction pattern was unchanged from Fig. 6b. 

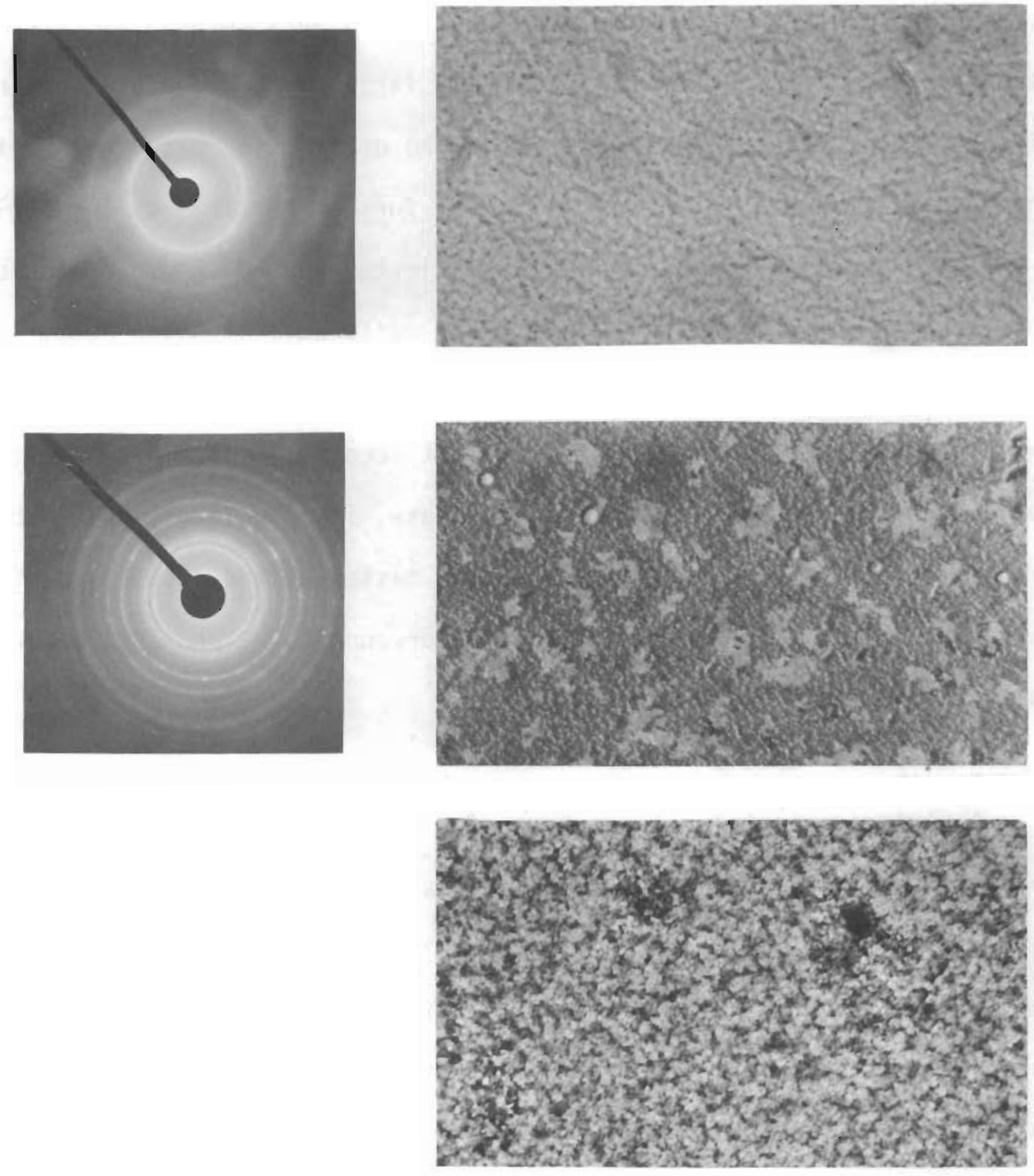

Figure 6

Electron diffraction patterns and photomicrographs of plutonium-5 $w t \%$ tantalum alloy. The degree of annealing by the imaging beam increased from a) to c). 
The interplanar spacings in the third column of Table II provide an acceptable fit to the beta plutonium structure. The major discrepancy was in the relative intensities. The 2.49 and $1.49 \AA$ lines would be expected to be more intense than the 2.90 and $1.76 \AA$ lines, however the opposite was observed.

Plutonium-1 Wt\% Zirconium Alloy

The remaining alloy investigated was plutonium- 1 wt $\%$ zirconium. The initial microstructure of this material is shown in Fig. 7a. Growth of the light contrast grains began immediately with observation of an area. The first-formed grains continued to grow and nucleated grains of different orientation (medium and dark gray, Fig. 7b) while new light contrast grains continued to form in the original matrix. This process continued, until the matrix was consumed. The final structure is shown in Fig. $7_{C}$. The diffraction pattern did not change significantly for the structures shown in Figs. 7b, and 7c. The interplanar spacings in the last column of Table II provide a reasonably good fit to the zeta phase with the exception of the first spacing, $3.28 \AA$. Since the first four spacings were obtained from the inner ring of the pattern, Fig. $7 c$, which is poorly resolved, this discrepancy is not regarded as significant. Comparison with Bulk Sputter Deposited Material Behavior

With the exception of the unalloyed plutonium, for which a satisfactory phase determination was not achieved, the in situ coated foil specimens crystallized in the structures expected for their compositions. The diffuse diffraction patterns obtained in the early stages of grain formation and growth, although not adequate for structure determination, 

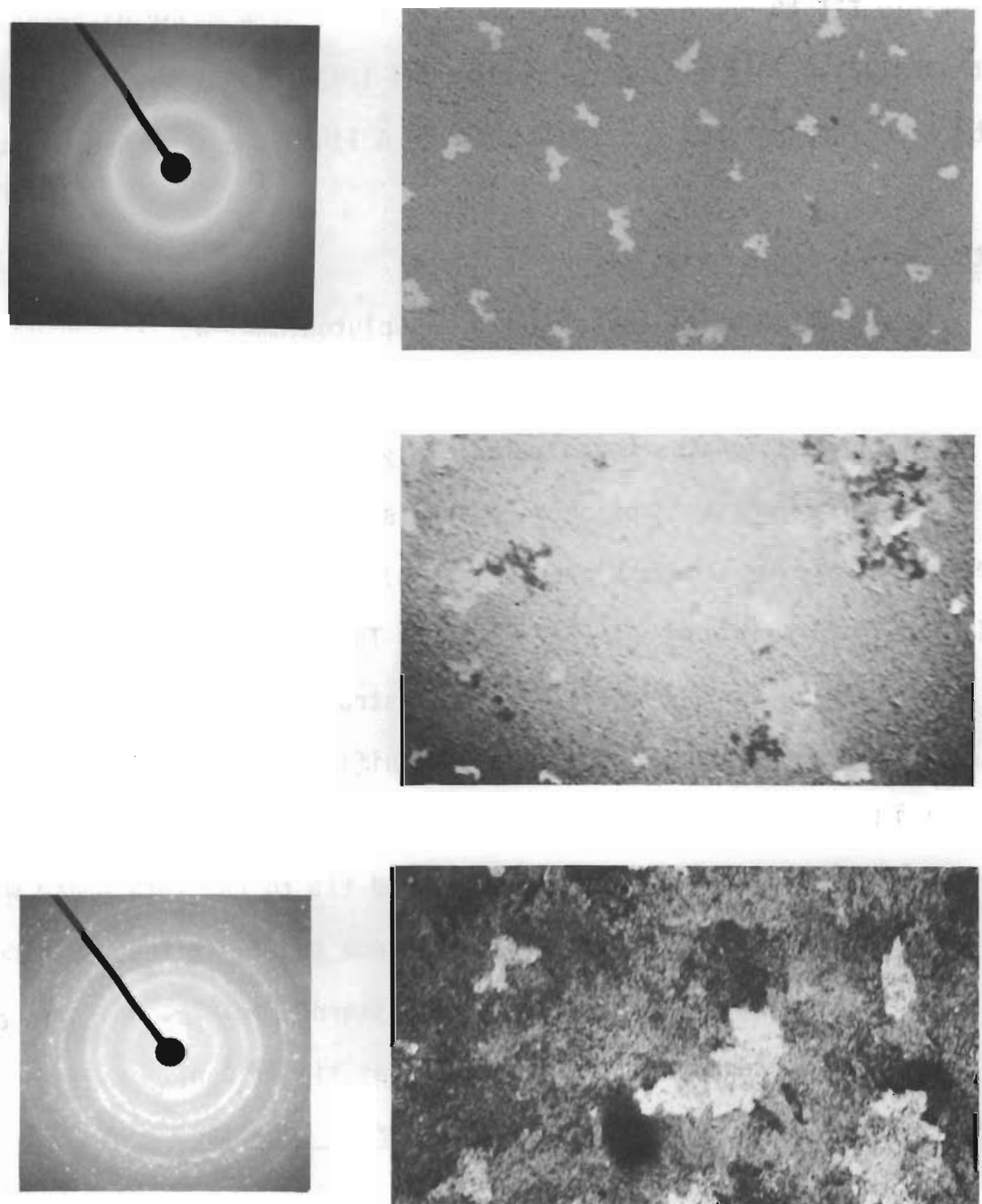

Figure 7

Electron diffraction patterns and photomicrographs of plutonium-1 wt\% zirconium alloy. The degree of annealing by the imaging beam increased from a) to $\mathrm{c}$ ). 
were consistent with the patterns obtained from the final stable structures. No evidence for intermediate phases, such as reported in various alloys rapidly quenched from the melt, ${ }^{(9)}$ was observed.

The coated foil specimens did deviate from bulk sputter deposited material behavior in two respects. First, they had no observable structure in the as-deposited condition; some degree of heating (by the imaging electron beam) was required to develop a resolvable structure. In contrast, bulk (e.g., $\geq 0.1 \mathrm{~mm}$ thick) deposits of these alloys prepared under similar deposition conditions, develop a fully crystalline structure. Second, the coated foils did not exhibit the allotropic behavior of bulk plutonium or its alloys. For example, no change in the diffraction patterns was observed upon heating to an estimated $450^{\circ} \mathrm{C}$ (based on the manufacturer's calibration of the hot stage furnace). This temperature range would have been expected to produce the alpha $\rightarrow$ beta $\rightarrow$ gamma $\rightarrow$ delta transformations in unalloyed plutonium; the beta $\rightarrow$ gamma $\rightarrow$ delta and delta $\rightarrow$ alpha on cooling in plutonium-tantalum; and the zeta $\rightarrow$ delta in plutonium-zirconium. The absence of these transformations may be due to the absence of three dimensional mechanical constraints in a thin foil or alternatively, to the constraint imposed by the protective beryllium films.

Since the coated foil behavior was not typical of bulk sputter deposited material, the original goal of the program could not be achieved. It was therefore decided to determine whether the coated foil structure obtained during deposition at higher substrate temperatures was more representative of thick deposits. If this were the case, the dependence of coated foil deposit structure on substrate temperature could be determined, at least over part of the range of interest. 
In the initial experiments, the cellulose acetate parting layer was used. The substrate holder was heated with a wire wound heater. placed in the water cooling tube, which was dry for these experiments. It was found that after exposure to temperatures above $100^{\circ} \mathrm{C}$, the cellulose acetate was incompletely soluble in acetone. The residue left on the thin foil sandwiches prevented useful observation in the electron microscope. Substrate cemperatures below this level resulted in initially unresolvable and unstable structures as observed previously. Since attempts to find a suitable parting layer for elevated temperature use were unsuccessful the effort was terminated.

Ion Thinning

The first group of experiments were intended to test the operation of the ion gun. Copper foil, 10 microns thick, was used as a nonradioactive stand-in for plutonium. The ion gun was operated at the maximum current levels recommended by the manufacturer, with the tightest available focusing of the beam. The specimen was bombarded for ten hours, which should have removed material to a depth of 4 microns. The absence of visible cratering of the specimen, together with discoloration of an $\sim$ centimeter diameter area of the specimen holder indicated that the ion beam was significantly more diffuse than specified. The peak intensity was about $10 \%$ of the expected value.

Discussions with the ion gun manufacturer revealed that the beam incensity specifications were based on the plane of the final electrode of the gun, and that the beam diverged rapidly from that point. The equipment was revised to permit the specimen-gun distance to be decreased, 
although this required using normal incidence rather than the desired 35 to $45^{\circ}$ incidence. Also, the ion gun was operated considerably beyond the recommended parameters in order to maximize the intensity at the beam center. A copper specimen was bombarded for a period of ten hours, producing a visible depression. However, the specimen holder was also visibly eroded around the specimen itself, and it appeared that some of this material had been redeposited on the specimen. Such deposition on a surface under ion bombardment generally produced roughening of the surface in the form of conical growths. ${ }^{(10)}$ It therefore appeared necessary to obtain an ion gun with tighter beam focusing, or else coat the specimen holder with a material; e.g., carbon, with a low sputtering yield.

It was apparent that greater beam intensity would also be necessary to produce the protective coating on the thinned sample, since in this case the geometry required prevented the beryllium target from being placed close to the ion gun.

The probability of success in this effort did not appear high enough to justify the cost of a more effective ion gun system, so the program was terminated.

\section{SUMMARY AND CONCLUSIONS}

Two approaches to the transmission microscopy of plutonium were examined. The first was primarily concerned with protecting the highly reactive plutonium thin foil from the atmosphere during transfer to the microscope and during observation in the microscope. Sandwiching the 
plutonium between thin layers (nominally $10 \mathrm{~nm}$ thick) of sputter deposited beryllium proved satisfactory. Observation of several plutonium alloys, sputter deposited to the desired thickness, were made.

The second approach was an attempt to use a thinning method which would be compatible with the above protective layer scheme, to produce electron-transparent samples from bulk or thick sputter deposited plutonium. Ion thinning was the method selected, but problems such as inadequate focussing of the ion beam, and extremely low metal removal rates, prevented successful thinning.

The coated foil specimens which were sputter deposited directly to an electron-transparent thickness $(220 \mathrm{~nm})$ had no resolvable structure when first illuminated by the electron beam. Small grains started forming within a few seconds. These grains grew rapidly, while additional new grains appeared; these processes continued until the originally featureless matrix was consumed and occupied by new grains. The details of the "Crystallization" differed somewhat between the alloys investigated. With the exception of unalloyed plutonium, the foils all ultimately developed the crystal structure expected in "bulk" sputtered deposits. The crystal structure of the unalloyed plutonium could not be established.

During heating and cooling experiments after the initial crystallization the foils did not exhibit the phase transformations expected on the basis of their composition. Foils were slowly heated to an estimated $450^{\circ} \mathrm{C}$ in the microscope hot stage without visible changes in either the grain structure or the diffraction pattern. The absence of phase 
transformations may have been due to the dimensions of the foils, or possibly the effect of the protective beryllium layers.

The discrepancies between thin foils and bulk sputter deposited plutonium, in both initial structure and subsequent phase transformation behavior, decrease the utility of the technique. The development of a suitable thinning technique is still required in order to gain useful structural information. 


\section{REFERENCES}

1. A. Brewer and F. Fraikor, J. Nucl. Mat., 21, 345, 1967.

2. D. Douglass and S. Bronisz, J. Nucl. Mat., 23, 107, -1967.

3. P. B. Hirsch, et al, "Electron Microscopy" of Thin Crystals," Butterworths, London, 1965.

4. R. Busch, Proc. 4th International Conference Plutonium and Other Actinides, October 1970, Santa Fe, New Mexico, 1970, pg 1037.

5. R. Busch, Proc. 4th International Conference Plutonium and Other Actinides, October 1970, Santa Fe, New Mexico, 1970, pg 1045.

6. P. B. Hirsch, et al, "Electron Microscopy of Thin Crystals," Butterworths, London, 1965, pg 1045.

7. Spacings were taken from the ASTM card file and in-house sources.

8. Plutonium Handbook, 0. J. Wick, Ed., Gordon and Breach, New York, 1967, Vol I, Page 39.

9. T. R. Anantharaman and C. Suryanarayana, J. Mat. Sci., 6, 1111 , 1971.

10. G. K. Wehner and D. J. Hajicek, J. Appl. Phys., 42, 1145, 1971. 


\section{DISTRIBUTION}

No. of

Copies

OFFSITE

3 AEC Albuquerque Operations office P.0. Box 5400

Albuquerque, New Mexico 87544

D. B. Anthony

F. J. Arrota

V. C. Vespe (Weapons Dev. Div.)

1 AEC Division of Military

Application

U.S. Atomic Energy Commission

Washington, D.C. 20545

Col. F. C. Cobb

1 AEC Dow Chemical USA

Rocky Flats Division

P.0. Box 938

Golden, Colorado 80401

B. W. Colson

189 AEC Technical Information Center

9 Dow Chemical

Rocky Flats Division

P.0. Box 888

Golden, Colorado 80401

H. E. Bowman

F. L. Collins

E. Jiannetti/W. H. Schmalhorst

L. W. Pribila

F. Springer

D. L. Strangfeld/J. L. Stakebake

M. A. Thompson

E. Vejvoda/L. R. Crisler

J. F. Willging

18 Lawrence Livermore Lab.

P.0. Box 808

Technica1 Information Dept., $\mathrm{L}-3$

Livermore, California 94550

G. A. Broadman
No. of

Copies

OFFSITE contd

Lawrence Livermore Lab. contd

C. T. Brockett

R. B. Carr

D. F. Cruff

C. R. Henry

E. I. Hill

P. T. Hibdon

A. J. Hodges/J. C. Behne

H. W. Kruger

W. E. Ne1son

H. N. Perl

R. Perlman

K. D. Perry

J. L. Robbins

L. W. Roberts

F. R. Wondolowski/ W. H. Hubbe 11

R. L. Wagner/ J. P. Diaconoff

J. W. Kury

8 Los Alamos Scientific Laboratories P.0. Box 1663 Los Alamos, New Mexico 87544

R. M. Alire (Group WX-2)

R. D. Baker

D. R. Harbur

S. S. Hecker

J. E. Hockett (Group WX-5)

L. Horpendah1

W. J. Maraman

F. W. Schonfeld

1 AEC Chicago Patent Group U.S. Atomic Energy Commission 9800 South Cass Avenue Argonne, Illinois 60439

A. A. Churm 
No. of

Copies

ONSITE

AEC Richland Operations Office

B. J. Melton

1 Atlantic Richfield Hanford Co.

A. E. Smith

18 Battel le-Northwest

V. C. Asmund

R. Busch

D. L. Condotta

H. R. Gardner

D. D. Hays

R. H. Jones

R. R. King

N. Laegreid

E. D. McClanahan

M. D. Merz

R. W. Moss

R. D. Nelson

J. W. Patten

R. W. Stewart

0. J. Wick

Technical Information Files 